\title{
Phenotype and Differentiation Potential of a Novel Rat Tracheal Epithelial Cell Line
}

\author{
Margaret M. Doherty, Jingyao Liu, Scott H. Randell, Charleata A. Carter, C. William Davis, \\ Paul Nettesheim, and Patrice C. Ferriola
}

Laboratory of Pulmonary Pathobiology, National Institute of Environmental Health Science, Research Triangle Park, North Carolina, and Departments of Pathology and Pulmonary Medicine, University of North Carolina at Chapel Hill, Chapel Hill, North Carolina

\begin{abstract}
In this report we described the establishment and characterization of a continuous rat tracheal epithelial (RTE) cell line spontaneously derived from secondary RTE cell cultures. Designated SPOC1, this cell line is nontumorigenic and maintains a diploid karyotype with specific, nonrandom chromosomal alterations involving chromosomes 1,3 , and 6 . SPOC1 cells demonstrate decreased requirements for peptide growth factors, compared with primary RTE cells. Upon inoculation into denuded rat tracheas, which are then implanted into syngeneic hosts, SPOC1 cells initially form a stratified squamous epithelium, which becomes less stratified with time and forms glandlike invaginations into the surrounding lamina propria. No evidence of ciliated cell differentiation is detected. The epithelium formed by SPOC1 cells in tracheal grafts reacts with antibodies specific for keratin 14, 13, and 19 (but not keratin 18) at both early and late time points, although the localization of antibody staining changes as the epithelium becomes less stratified with time. The suprabasal epithelial cells become positive for alcian blue-periodic acid-Schiff staining at later time points. The near-normal karyotype and differentiation potential of SPOC1 cells make this cell line a unique window into early changes occurring during immortalization of airway epithelial cells and will allow studies of relationships between differentiation state and neoplastic transformation.
\end{abstract}

The development of cancer is a multistep process in which molecularly altered progenitor cells clonally expand in response to proliferative stimuli $(1,2)$. Both genetic and epigenetic influences on this altered population lead to progressive loss of key growth regulatory features and neoplastic transformation. Lung neoplasms are the most frequent human cancers, and primary lung cancer is divided into four major histologic subtypes. The predominant forms of bronchogenic carcinoma include squamous cell carcinoma, adenocarcinoma, and adenosquamous carcinoma. It is not known, however, which airway cells are the progenitors for these lung carcinomas. The major cell types in the tracheal and proximal bronchial epithelium are basal, ciliated, and

(Received in original form May 31, 1994 and in revised form September 8, 1994)

Address correspondence to: Patrice C. Ferriola, Department of Cellular and Molecular Toxicology, Chemical Industry Institute of Toxicology, 6 Davis Drive, Research Triangle Park, NC 27709.

Abbreviations: alcian blue-periodic acid-Schiff-hematoxylin, AB-PAS; bovine pituitary extract, BPE; complete serum-free medium, CSFM; diaminobenzidine, DAB; epithelial growth factor, EGF; enhanced growth variant, EGV; fibronectin, Fn; hematoxylin and cosin, H\&E; monoclonal antibody, mAb; phosphate-buffered saline, PBS; transepithelial resistance, $\mathbf{R}_{i}$; rat tracheal epithelial, RTE; spontaneously derived in complete serumfree medium, SPOC; transepithelial electrical potential difference, $V_{1}$.

Am. J. Respir. Cell Mol. Biol. Vol. 12. pp. 385-395, 1995 secretory (mucous and serous) cells, and in the bronchioles, Clara and ciliated cells. Cells capable of cell division, and therefore candidates for neoplastic transformation include basal, secretory, and Clara cells $(3,4)$. Identifying the target cells for lung cancers would greatly facilitate our understanding of the cellular and molecular mechanisms involved in lung cell neoplastic progression.

In vitro models have been widely used to study better the molecular and cellular alterations in the various forms of lung cancer. Immortalized human cell lines have been established from lung tumor tissue (5) and by transformation of primary tracheobronchial epithelial cells with DNA tumor viruses, such as SV40 (6) and cooperating oncogenes $(7,8)$. However, there are only a few reports that describe human airway epithelial cell lines that maintain their differentiated phenotype $(9,10)$. Such cell lines would be valuable for studying the progenitor cells of airway neoplastic disease.

Our laboratory has been studying neoplastic progression in rat tracheal epithelial (RTE) cells in vitro. Carcinogen exposure of primary RTE cells results in the development of enhanced growth variants (EGV) (11). A certain percentage of EGV can be expanded into cell lines, and some of these cell lines form tumors upon injection into nude mice. Characterization of growth requirements for EGV cell lines reveals that they are less dependent on exogenous growth factors than are primary RTE cells $(12,13)$, and they have 
alterations in expression and organization of extracellular matrix proteins (14). Aberrations in chromosome number and structure, some of which are nonrandom, have been noted in all EGV cell lines $(15,16)$. Of particular interest is the disparity in differentiation potential between primary RTE cells and EGV cell lines. Primary RTE cells repopulate denuded tracheas with a normal pseudostratified mucociliary epithelium, whereas EGV cell lines from a keratinizing squamous epithelium and neoplastic EGV cells form invasive squamous cell tumors when transplanted (17). Thus, the RTE transformation system apparently selects for cells with a squamous pattern of differentiation, which is a phenotype seen in preneoplastic and neoplastic tracheobronchial lesions (11).

In this report we describe the establishment and characterization of a continuous RTE cell line spontaneously derived from secondary RTE cell cultures. Designated SPOCl (spontaneously derived in complete serum-free medium), this cell line is nontumorigenic and, unlike any other RTE cell line, maintains a diploid karyotype with specific, nonrandom chromosomal alterations. Although similar to other RTE cell lines in having reduced growth factor requirements compared with primary RTE cells, SPOCl cells are unique in their ability to differentiate into a pseudostratified epithelium with glandlike structures in denuded tracheal grafts. The near-normal karyotype and differentiation potential of SPOCl cells make this cell line a useful tool for studying early cellular and molecular alterations associated with airway epithelial cell multistep carcinogenesis.

\section{Materials and Methods \\ Primary RTE Cell Culture}

Epithelial cells were isolated from the tracheas of 10- to 14wk-old Fischer 344/NCR rats by protease digestion as previously described (12). Primary RTE cells were plated at a density of $1 \times 10^{4}$ cells $/ 60-\mathrm{mm}$ dish in complete serumfree medium (CSFM) consisting of Ham's F-12 media containing $5 \mathrm{ng} / \mathrm{ml}$ epithelial growth factor (EGF) and $5 \mu \mathrm{g} / \mathrm{ml}$ transferrin (Collaborative Research, Waltham, MA), $5 \mu \mathrm{g} / \mathrm{ml}$ insulin, $0.1 \mu \mathrm{g} / \mathrm{ml}$ hydrocortisone, $0.1 \mu \mathrm{g} / \mathrm{ml}$ cholera toxin, $50 \mathrm{mM}$ ethanolamine and phosphoethanolamine, $0.8 \mathrm{mM}$ $\mathrm{CaCl}_{2}, 1.5 \mathrm{mg} / \mathrm{ml}$ bovine serum albumin, essentially globulin free (Sigma Chemical Co., St. Louis, MO), $0.1 \mu \mathrm{g}$ protein $/ \mathrm{ml}$ of bovine pituitary extract (BPE) and $15 \mathrm{mM}$ Hepes, pH 7.3 (Sigma), cultured in a humidified $5 \% \mathrm{CO}_{2} / 95 \%$ air environment at $37^{\circ} \mathrm{C}$. Medium was changed $1 \mathrm{~d}$ after plating and subsequently every other day.

\section{Secondary RTE Cell Culture and Establishment of Cell Line}

The scheme for generation of the SPOCl cell line is shown in Figure 1. On Day 41 of primary culture, cells were trypsinized, centrifuged to remove trypsin, and counted. After counting, cells were seeded into $60-\mathrm{mm}$ dishes at a density of 1000 cells/dish (clonal density). Cells were grown under the same conditions as primary cultures.

When secondary cultures were 1 mo old, the cells from five dishes were pooled (10 to 20 colonies visible per dish) and plated at a density of $4 \times 10^{5}$ cells in a $25-\mathrm{cm}^{2}$ flask and grown to $80 \%$ confluency at which time cells were pas-

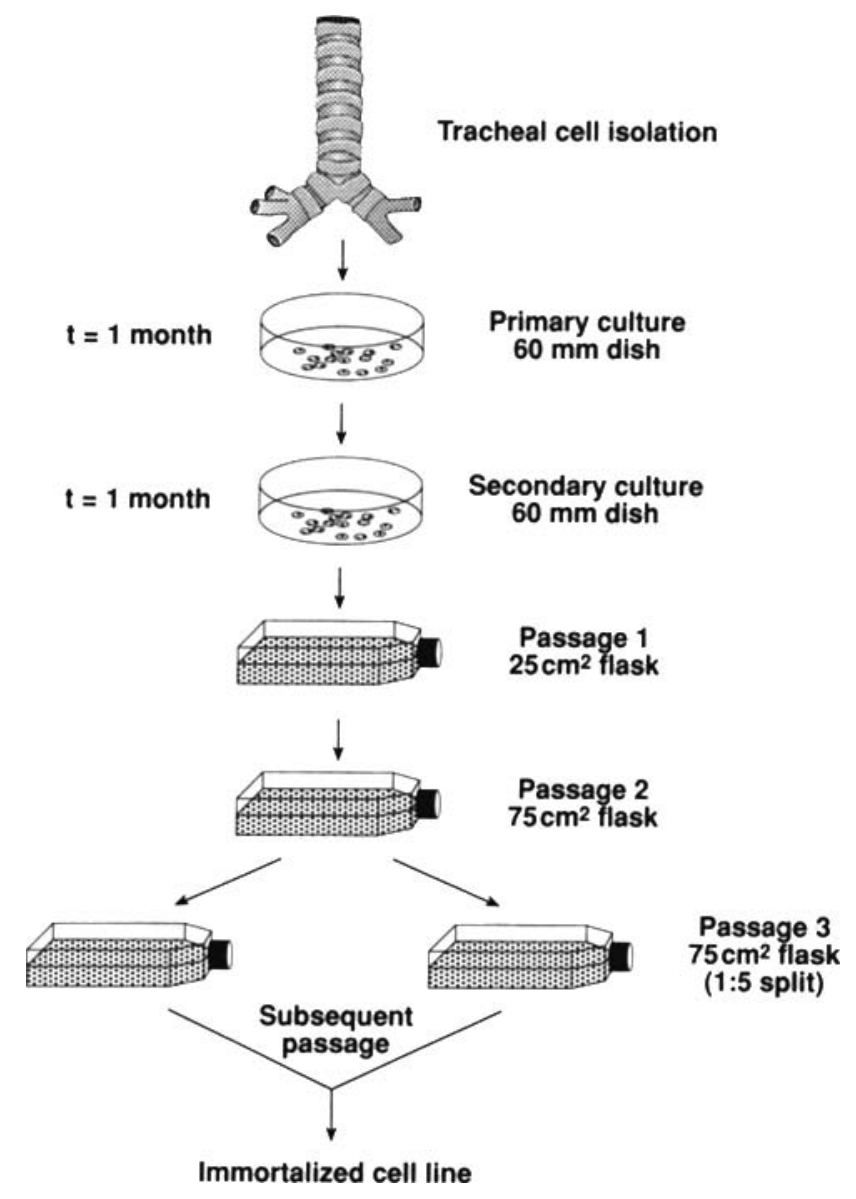

Figure 1. Diagram of the steps taken in establishing the SPOC1 cell line.

saged into $75-\mathrm{cm}^{2}$ flasks (1:1) and designated as $\mathrm{SPOCl}$, passage 1. At $80 \%$ confluence, the cells were split (1:5) into $75-\mathrm{cm}^{2}$ flasks. Cells were continuously passaged at $80 \%$ confluence, 1:10 split, for $>31$ passages $(>100$ population doublings) and were considered a continuous cell line.

For some experiments, cells were plated at $2 \times 10^{4}$ cells/well onto Transwell-Col tissue culture inserts (Costar, Cambridge, MA), which have been shown to promote differentiation of primary RTE cells in vitro (18). Culture methods were essentially the same as those on plastic, except that cells were directly plated on inserts in medium consisting of a 1:1 mixture of Dulbecco's modified Eagle's medium and F-12 medium and the supplements described previously (18). In addition, some cultures received $5 \times 10^{-8} \mathrm{M}$ retinoic acid, which promotes mucociliary differentiation in primary RTE cells (18). When SPOC1 cultures were confluent, medium was removed from the apical surface, and cells received fresh medium every other day in the basolateral compartment only.

To determine colony forming efficiency of SPOCl cells, cells were plated on plastic at clonal density at passages 3 , $5,10,15,20$, and 25 . The colony-forming efficiency was determined from the average number of colonies on three dishes at Day 10 divided by the number of cells plated per dish.

Growth curves for different passage SPOCl cells were 
generated by plating cells on $60-\mathrm{mm}$ culture dishes at a cell density of 1 to $5 \times 10^{4} \mathrm{cells} /$ dish. At the indicated times, triplicate dishes were washed in phosphate-buffered saline (PBS) and trypsinized, and the cells were counted using a Coulter counter. Some cells were plated in CSFM medium, but changed to medium without insulin, EGF, BPE, or both EGF/BPE $1 \mathrm{~d}$ after plating. For all growth conditions, medium was then replaced every other day for the duration of the experiment. Growth curve experiments were repeated at least 2 times.

\section{Cytogenetics and Karyotyping}

Logarithmically growing cells from passages 4 and 28 were incubated with colcemid $(0.05 \mu \mathrm{g} / \mathrm{ml}$, final concentration) in CSFM for 15 to $45 \mathrm{~min}$. Cells were detached by trypsinization, transferred to a $15-\mathrm{ml}$ centrifuge tube, and collected by centrifugation. Supernatant was decanted, and cells were resuspended in hypotonic solution. Cells were fixed in a 3:1 methanol:glacial acetic acid fixative and after fixation, spread on slides and allowed to air dry. For G-banding, slides were immersed in trypsin solution (0.025\% in PBS, pH 6.8), rinsed in PBS, and stained in 5\% Giemsa, pH 6.8. Chromosome analysis was made according to the standardized nomenclature for rat chromosomes (19). At least 30 metaphases were analyzed to determine the modal karyotype of SPOCl cells at passages 4 and 28. Recurrent chromosome abnormalities were noted.

\section{Tumorigenicity Analysis}

At passage 28, cells were injected into anesthetized nude mice $(\mathrm{Nu} / \mathrm{Nu} \mathrm{Balb} / \mathrm{c})$. Two sites per mouse were inoculated with $200 \mu \mathrm{l}$ of Ham's F-12 containing either 4 or $2 \times 10^{6}$ cells per inoculum. Control animals were injected with 200 $\mu \mathrm{l}$ of F-12. Mice were monitored weekly for $1 \mathrm{yr}$ for the appearance of tumor nodules.

\section{Tracheal Grafts}

Tracheas to be inoculated with SPOC1 cell suspensions were obtained from male F344 rats 8 to $16 \mathrm{wk}$ of age. The tracheas were frozen at $-20^{\circ} \mathrm{C}$ and thawed $1 \mathrm{~h}$ later. This was repeated 4 times. Before use, frozen tracheas were thawed, and the distal ends were sealed with a silk suture. Each trachea was then inoculated with $1 \times 10^{4}$ cells resuspended in $50 \mu \mathrm{l}$ of Ham's F-12 medium, and the proximal end was tied with another suture. Transplants were placed subcutaneously onto the backs of syngeneic rats.

Tracheal grafts were harvested on Day 7 and Day 21 after implantation and prepared for histology and immunohistochemistry as previously described (20). Briefly, grafts were cut into rings and fixed with OmniFix II (An-Con Genetics, Melville, NY) or 4\% PFA in PBS, embedded in paraffin and stained with hematoxylin and eosin (H\&E), alcian blue (pH 2.5)-periodic acid-Schiff-hematoxylin (ABPAS), or cell type-specific monoclonal antibodies (mAb). Sections were deparaffinized, rehydrated, and stained as previously described (20), and peroxidase activity was visualized using a 6-min incubation in diaminobenzidine (DAB)$\mathrm{H}_{2} \mathrm{O}_{2}$ solution $\left(20 \mathrm{mg}\right.$ DAB and $100 \mu \mathrm{l}$ of $3 \% \mathrm{H}_{2} \mathrm{O}_{2}$ in 100 $\mathrm{ml}$ of $0.05 \mathrm{M}$ Tris buffer, $\mathrm{pH} \mathrm{7.6)}$. The slides were counterstained with $1 \%$ methyl green. For negative controls, hybridoma supernatants were replaced with equal dilutions of NS 1 myeloma cell-conditioned medium plus normal mouse serum immunoglobulin $\mathrm{G}(50 \mu \mathrm{g} / \mathrm{ml})$.

Five different $\mathrm{mAb}$, whose reactivity with normal RTE cells has been characterized $(18,21,22)$, were used to determine cell type-specific reactivity of SPOC1 cells in grafts. mAb LL002 (kindly provided by Dr. E. B. Lane, Dundee, $\mathrm{UK}$ ) reacts with human keratin 14 and is specific for basal cells in many epithelia, including the rat trachea. Keratin 13 was detected with mAb AE8 (ICN, Costa Mesa, CA) and is a marker for squamous epithelium (23). mAb CK18-2 (kindly provided by Dr. F. C. S. Ramaekers, Maastricht, The Netherlands) reacts with human keratin 18 and strongly stains columnar-type epithelial cells in the rat trachea and in primary RTE cell cultures $(18,22)$. Keratin 19 was detected with mAb RTE 1, which has previously been shown to react with most epithelial cells in intact adult rat tracheas $(21,22)$. The presence of ciliated cells was assessed with mAb RTE 3 , previously shown to be specific for an epitope expressed by ciliated cells in vivo (22).
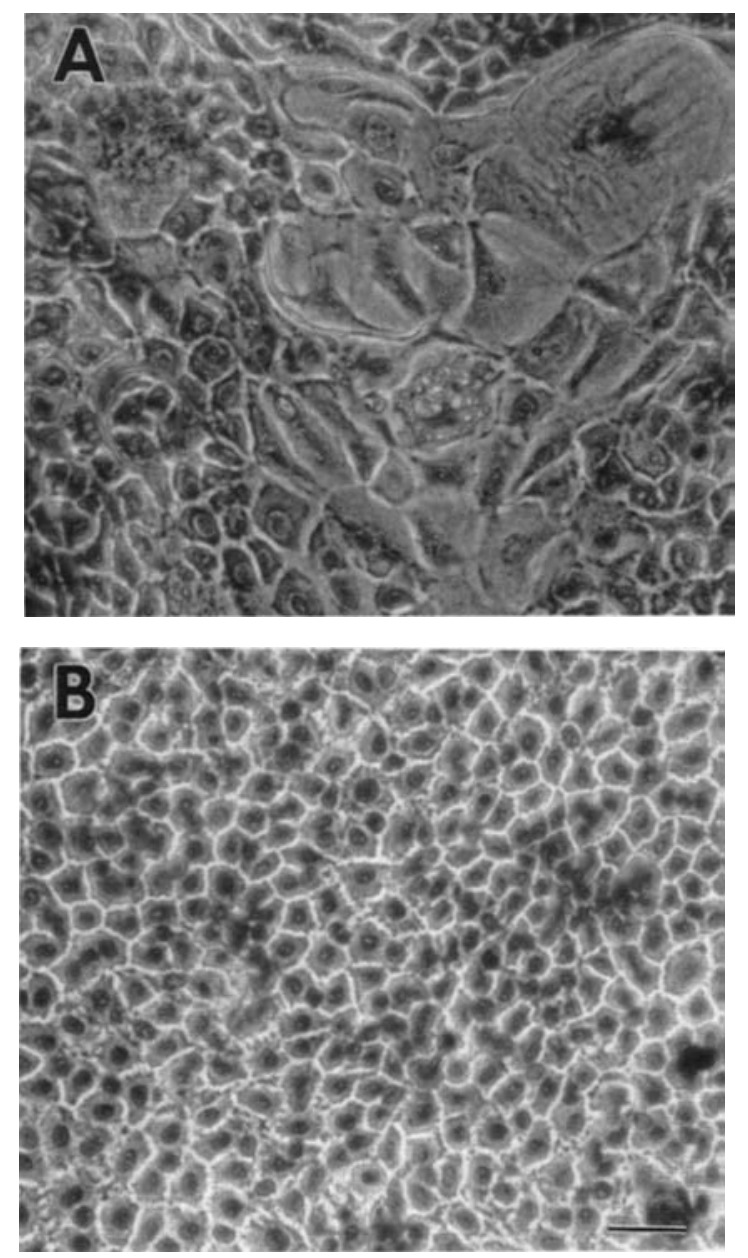

Figure 2. Phase-contrast microscopy of primary $(A)$ and secondary $(B)$ RTE cell culture morphology. Primary RTE cells propagated for $1 \mathrm{mo}$ in CSFM were trypsinized and replated into secondary culture under the same growth conditions. At the same stage in culture, primary cells appear larger and more heterogeneous than cells in secondary culture. Bar $=50 \mu \mathrm{m}$. 


\section{Electron Microscopy}

Before fixation for electron microscopy, SPOC1 cells (passage 8) were plated onto four-well, plastic Lab-Tek tissue culture slides in CSFM medium and allowed to proliferate until they were almost confluent. Cultured cells were fixed overnight with a $3 \%$ glutaraldehyde solution in CSFM at $37^{\circ} \mathrm{C}$ and postfixed in $1 \%$ osmium tetroxide in $0.1 \mathrm{M}$ Sorensen's phosphate buffer for $1 \mathrm{~h}$ and transferred to $30 \%$ ethanol for $5 \mathrm{~min}$. Cells were stained in $2 \%$ uranyl acetate in $30 \%$ ethanol and dehydrated and embedded in Polybed 812 (Polysciences, Inc., Warrington, PA). Ultrathin sections were cut en face at $70 \mathrm{~nm}$ using an LKB Ultramicrotome (Leica), mounted on uncoated copper grids and poststained with $4 \%$ aqueous uranyl acetate and $0.4 \%$ lead citrate. All sections were examined with a Zeiss $10 \mathrm{~A}$ transmission electron microscope at $80 \mathrm{kV}$.

\section{Bioelectric Properties of SPOC1 Cells}

Transepithelial electrical potential difference $\left(V_{t}\right)$ and resistance $\left(R_{1}\right)$ of confluent SPOCl cultures grown on 24-mm Transwell-Col inserts (Costar) in the presence of retinoic acid were measured daily. $V_{1}$ was determined by placing the tips of sterile calomel electrodes in the media, bathing the apical and basolateral sides of the cultures. Calomel electrodes were coupled to an electrometer (custom unit, input impedance $>10^{10} \Omega$ ). Constant transepithelial current, generated by a stimulus isolation unit (World Precision Instruments, 305-B) was passed from platinum electrodes, which were wrapped around the tips of the calomel electrodes. Values of $R_{t}$ were corrected for the resistance of the culture insert and media by subtracting the voltage drop associated with the insert alone $(0.7 \mathrm{mV}, 100 \Omega)$ from the total change in $V_{1}$ determined when passing current.

\section{Analysis of mRNA Expression}

Total RNA was isolated from passage 8 SPOCl cells by the method of Chirgwin and colleagues (24), and the level of fibronectin (Fn) RNA determined by Northern analysis (25). Total RNA (10 to $20 \mu \mathrm{g}$ ) was electrophoresed through $1 \%$ agarose/formaldehyde gels, transferred to Nitroplus 2000 (MSI Inc., Westboro, MA) and hybridized to ${ }^{32} \mathrm{P}-\alpha-\mathrm{dCTP}$ labeled cDNA probes as described previously (26). Rat Fn cDNA was an ECOR1 0.5-kb fragment, which includes the coding sequence for the cell, heparin, and fibrin-binding domains (27). Equal loading of RNA samples was assessed by photographing ethidium bromide-stained gels before transfer and using a laser densitometer to scan the negatives. Autoradiographs of the Northern blots were also scanned by the densitometer, and gene expression was normalized to RNA loading.

\section{Results \\ In Vitro Growth Characteristics and Morphology of SPOC1 Cells}

After $4 \mathrm{wk}$ in primary culture, RTE cell size and shape were heterogeneous, and the cultures appeared squamous (Figure 2A). These cultures were replated in CSFM at clonal density and maintained in secondary culture for an additional $4 \mathrm{wk}$. Cells grew in tightly packed colonies (10 to 20 per dish), and the resulting cell population is shown in Figure 2B. Secondary cultures had a greater nuclear-to-cytoplasmic ratio than primary RTE cells, and cell shape was more homogeneous than the parent culture. The secondary cultures of RTE cells were similar in appearance to EGV colonies, which arose after MNNG treatment of primary RTE cells (28).

Early-passage (before passage 10) SPOCl cells were separated by wide intercellular spaces, except for occasional filopodia connecting cells, as shown in the electron micrograph in Figure 3. Desmosomes and tonofilament bundles could be identified but not with the frequency seen in proliferating primary RTE cells in culture (29). Although tight junctions were not apparent in cells grown on plastic, SPOC1 cells (passages 8 through 15) grown on permeable TranswellCol supports in the presence of retinoic acid developed a significant transepithelial resistance. Figure 4 shows the development of $V_{t}$ and $R_{t}$ as a function of time in culture for three successive passages. Both bioelectric parameters were generally low at the day of confluence and developed over a period of 5 to $7 \mathrm{~d}$. The mean $V_{t}$ and $R_{t}$ for Day 11 through 15 SPOC1 cultures was $-0.42 \pm 0.01 \mathrm{mV}$ and $385 \pm$ $21 \Omega \mathrm{cm}^{2}$, respectively $(n=3)$. The development of the bioelectric parameters coincided with development of the original confluent monolayer of cells into three to four layers of cuboidal cells, with some areas of each culture exhibiting
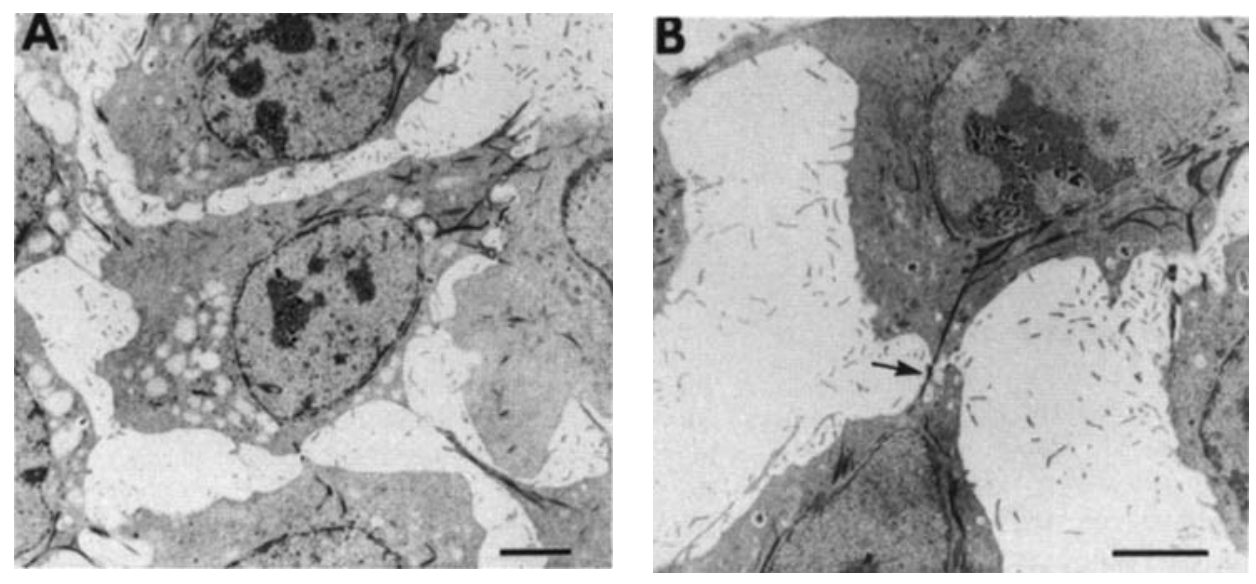

Figure 3. Panels $A$ and $B$ : Electron micrographs of passage 8 SPOC1 cells in culture. Cells were propagated on plastic in CSFM and fixed for electron microscopy on Day 6 in culture. Cells have a high nuclear-to-cytoplasmic ratio and display few intercellular contacts, with only occasional cell extensions forming cellular junctions (arrow). Bar $=4 \mu \mathrm{m}$. 
Figure 4. Bioelectric parameters of $\mathrm{SPOCl}$ cells propagated on Transwell-Col inserts at an airliquid interface. Transepithelial resistance $\left(R_{t}\right)$ and membrane potential $\left(V_{t}\right)$ were measured in serial passages of $S P O C 1$ cultures for $25 \mathrm{~d}$, beginning at confluence. Both bioelectric parameters were generally low at the day of confluence and developed over a period of 5 to $7 \mathrm{~d}$. The mean $V_{t}$ and $R_{t}$ for Days 11 through 15 SPOC1 cultures was $-0.42 \pm$ $0.01 \mathrm{mV}$ and $385 \pm 21 \Omega \mathrm{cm}^{2}$, respectively $(n=3)$.
Figure 5. Growth curves for passage 9 and passage 27 SPOC1 cells. Cells were plated at $5 \times$ $10^{4}$ cells/dish in CSFM. On Day 1 , cells were refed with CSFM or medium lacking the indicated growth factors. Early-passage cells have similar maximum cell densities regardless of medium composition; however, cells grown in CSFM reach plateau phase sooner than cells grown in other media. Similar doubling times ( $24 \mathrm{~h}$ ) and maximum cell densities are seen regardless of the medium composition with laterpassage cells. Repeats of this experiment yielded similar results.
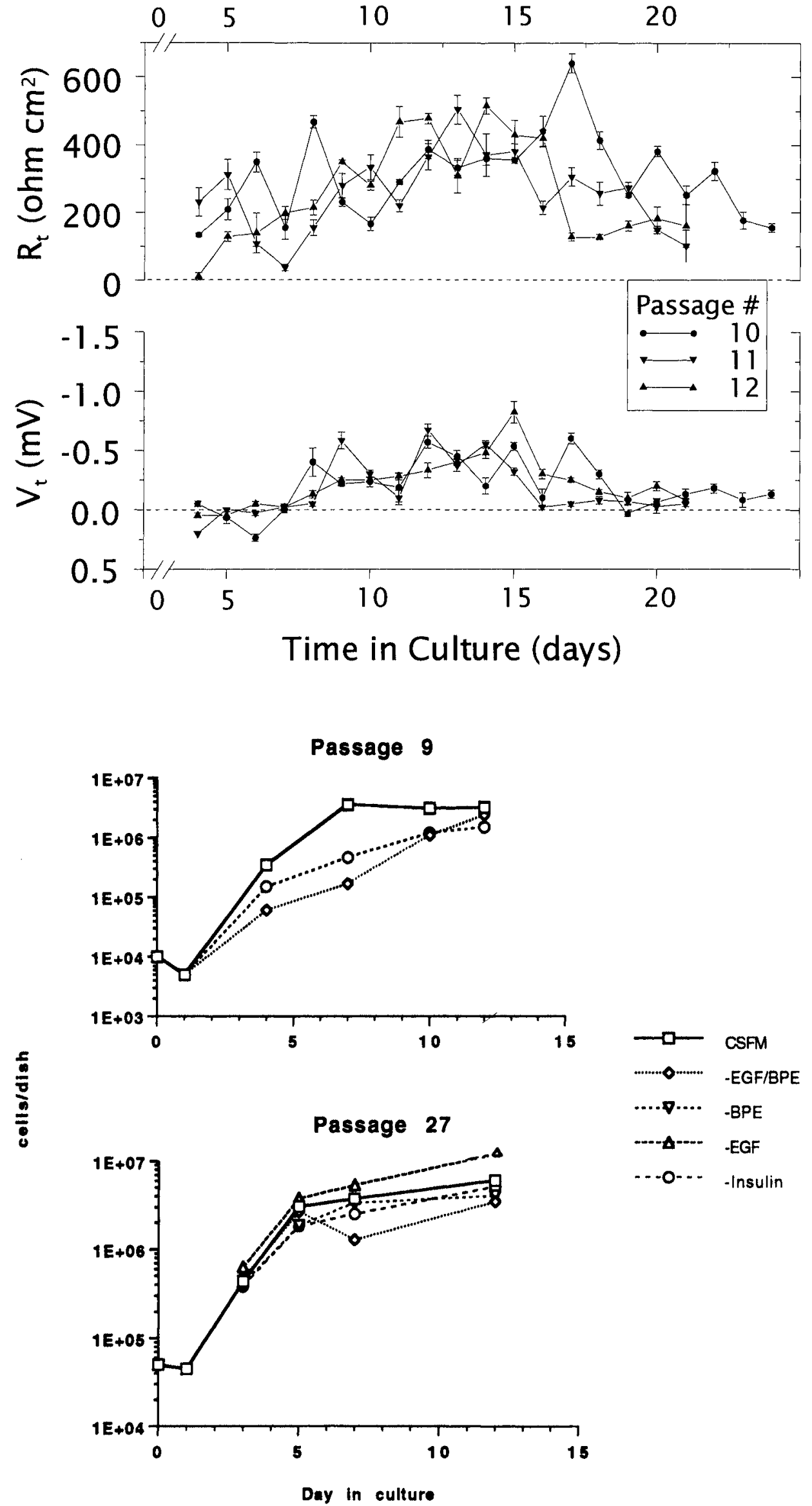

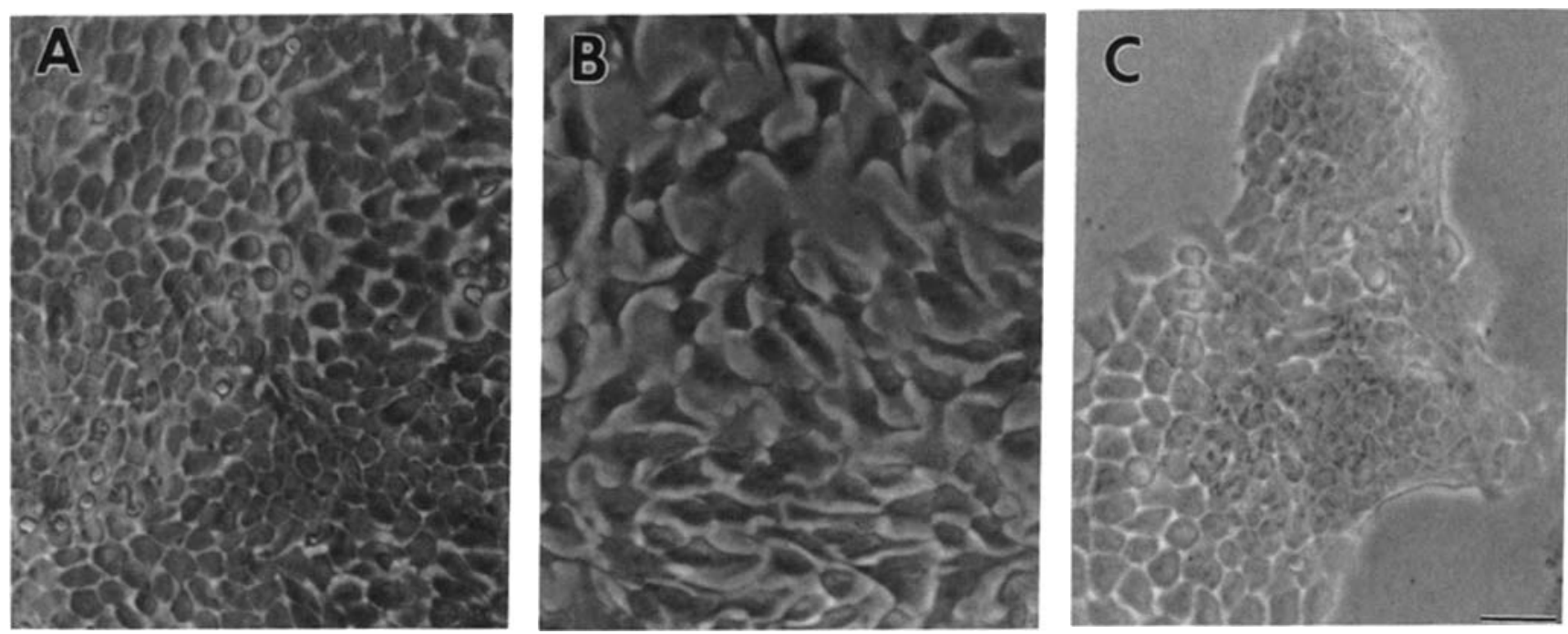

D

\section{Growth Condition}

\section{Relative Fn Expression}
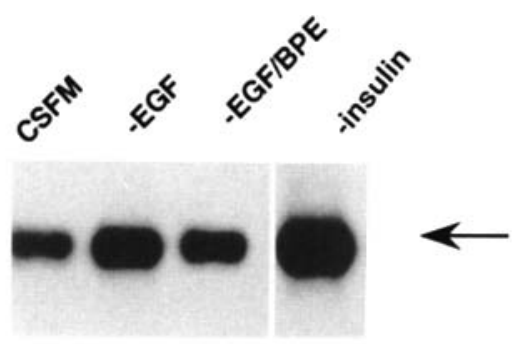

Fn
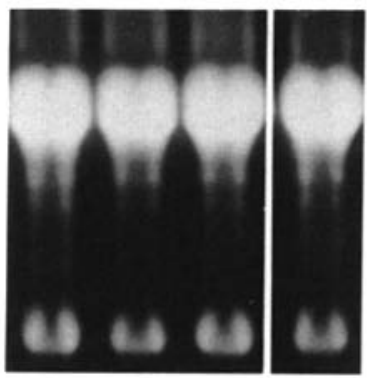

$18 s$
32

16
Figure 6. Phase-contrast microscopy of SPOC1 cells propagated until Day 13 in $\operatorname{CSFM}(A)$; medium without EGF and BPE $(B)$; and medium without insulin $(C)$. Cells cultured without EGF/ BPE are larger and more stellate in appearance, whereas those grown without insulin are smaller and grow in tightly packed colonies. Bar $=50 \mu \mathrm{m}$. Analysis of fibronectin mRNA expression in SPOC1 cells $(D)$. RNA was isolated from SPOCl cells during late logarithmic growth phase for cells grown in CSFM or in media without EGF, $\mathrm{EGF} / \mathrm{BPE}$, or insulin. Relative expression of $\mathrm{Fn}$ is shown and indicates that removal of factors increases Fn expression, with the greatest increase seen when insulin is removed from growth medium. squamous cell differentiation (data not shown). SPOCl cells grown on these supports did not develop cilia, but cuboidal cells stained positive for AB-PAS and contained mucous granulelike structures, as shown by TEM (data not shown). These data indicate that SPOC1 cells display both squamous and mucosecretory (but not ciliated) cell differentiation potential in vitro.

Colony-forming efficiency was determined at passages 3 , $5,10,15,20$, and 25 for SPOC1 cells grown on plastic. Efficiency increased with passage number and was stable by passage 25 (data not shown). These replating efficiencies are similar to those seen in EGV cell lines.

Growth curves comparing proliferation of passages 9 and 27 SPOC1 cells propagated in CSFM or in medium lacking certain growth factors are shown in Figure 5. These growth factors have previously been shown to be required for maximum growth of primary RTE cells but not EGV cell lines
$(12,26)$. Removal of insulin, EGF, and/or BPE from the growth medium $1 \mathrm{~d}$ after plating had no significant effect on the maximal cell number achieved by passage $9 \mathrm{SPOCl}$ cells. However, the time it took to reach maximum cell density was increased when the growth factors were removed from passage 9 cells. Statistics on replicate experiments showed significant differences between the control and minus insulin or minus EGF/BPE conditions on Day 7 in culture (Student's $t$ test, $P<0.05, n=3$ ). Differences in logarithmic growth were not observed with passage 27 SPOC1 cells.

Although growth factor removal did not affect maximum cell density, the morphology of SPOC1 cells was affected by growth factor removal, as shown in Figure 6. Figure 6A shows a phase-contrast micrograph of passage 28 SPOC1 cells grown in CSFM for $13 \mathrm{~d}$. Cell size and shape were homogeneous. Figure 6B shows SPOC1 cells grown in medium lacking EGF and BPE, and Figure 6C shows cells grown in 
Passage 31

Passage 4

Figure 7. Ploidy of SPOCl cells at passages 4 and 31 . At both early and late passages, SPOC1 cells have a diploid modal chromosome complement. At the early passage, there is a greater frequency of random chromosome loss, whereas at the later passage, a greater frequency of tetraploidy and random extra chromosomes occurs.
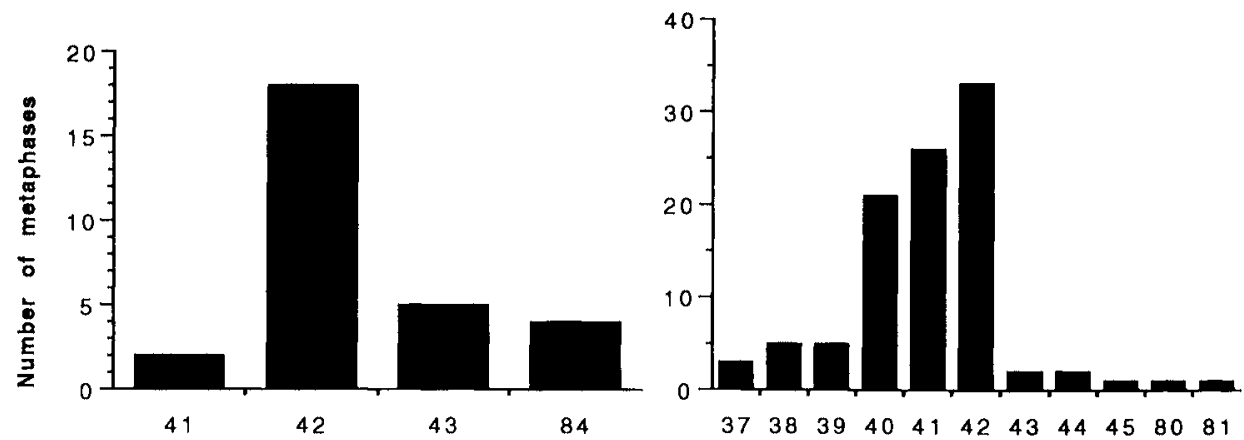

Chromosome number

medium lacking insulin. Cells propagated without EGF and BPE were larger and more stellate in appearance. Cells grown in medium without insulin grew in tightly associated colonies of cells rather than spreading and forming a confluent monolayer. We have previously shown that the morphology of primary RTE cells is altered by growth factor removal (26) and that Fn is a major cellular glycoprotein regulating RTE cell spread and morphology (30). We have also shown that Fn expression and organization are altered in SPOCl cells relative to primary RTE cells (14). To determine whether growth factor effects on morphology are mediated by changes in Fn levels, we assessed whether Fn levels were altered by growth factor removal from SPOC1 cells. RNA was isolated from SPOC1 cells grown in CSFM, medium without EGF and BPE, and medium without insulin and hybridized to a Fn cDNA. As shown in Figure 6D, Fn RNA levels were significantly increased in cells grown without insulin, but in contrast to primary RTE cells, were not altered by removal of EGF or BPE.

\section{Cytogenetic Analysis of SPOC1 Cells}

Chromosome counts were performed on cells from cultures at passages 4,17 , and 28 . Results from each passage were similar in that all passages had a modal chromosome number of 42 , which indicates that SPOC1 cells retain a diploid karyotype (Figure 7). Polyploidy was evident in only a few cells.

Karyotyping of passage 31 cultures demonstrated several nonrandom chromosome alterations, which are summarized in Table 1. All cells examined contained structural alterations involving chromosomes $1,2,6$, and 17. Chromosomes 1 and 2 were translocated, with breakpoints at p13 and q12, respectively. A second translocation involving the long arm of chromosome 6 and the short arm of chromosome 17 was also seen in $100 \%$ of cells examined. In $38 \%$ of metaphase spreads examined, a translocation of chromosome 3 was seen, which resulted in an isochromosome. Marker chromosomes and double minute chromosomes were occasionally seen in cells.

Tumorigenicity and Regeneration Potential of SPOC1 Cells

Late-passage SPOC1 cells were injected into nude mice to determine whether they had acquired neoplastic potential in vivo. Subcutaneous injections of two concentrations of passage 28 SPOC 1 cells failed to produce any tumors after $1 \mathrm{yr}$.

The regenerative and differentiation potential of SPOC1 cells was determined by inoculating denuded Fischer 344 rat tracheas with cell suspensions of SPOC1 cells. Samples were prepared from tracheas on Days 7 and 21 for morphologic characterization at the light-microscopic level. Figure 8 shows H\&E-stained sections of tracheas repopulated with passage 8 SPOCl cells. By Day 7, a confluent epithelium was established, which was predominantly multilayered and composed of cuboidal basal and suprabasal layers. The superficial layers resembled a stratified squamous epithelium (Figures 8A and 8B). The cytoplasm of the cells in the apical stratified layers was highly eosinophilic, but areas of dense cornification were not seen. The epithelium of Day 21 tracheas had thinned considerably and had an overall pseudostratified rather than a squamous appearance (Figures $8 \mathrm{C}$ and 8D). Glandlike invaginations into the submucosal tissue were frequently seen. Cells situated at the basal lamina maintained a basal cell-like appearance. The more columnar cells contained a clear, frothy cytoplasm suggestive of secretory granules. This apparent secretory differentiation was also seen in the glandular structures. The frothy cytoplasmic areas of the columnar cells of both the surface epithelium and the glands were AB-PAS positive (Figure 9). No AB-PAS staining was observed in the Day 7 epithelium. There was no evidence of ciliated cell differentiation in grafts.

\section{Expression of Differentiation Markers by Regenerated Tracheal Epithelium}

Tracheal grafts repopulated with SPOC1 cells were stained with a panel of antikeratin antibodies. The results are shown

TABLE 1

Nonrandom structural chromosome alterations in SPOC1 cells

\begin{tabular}{lccc}
\hline $\begin{array}{l}\text { Passage } \\
\text { No. }\end{array}$ & $\begin{array}{c}\text { Modal Chromosome } \\
\text { No. }\end{array}$ & Abnormality* & $\begin{array}{c}\text { Frequency } \\
(\%)\end{array}$ \\
\hline 4,31 & 42 & $\mathrm{~T}(1 ; 2)(\mathrm{p} 13 ; \mathrm{q} 12)$ & 100 \\
31 & 42 & $\mathrm{~T}(6 ; 179)(\mathrm{q} 11.1 ; \mathrm{p} 11)$ & 100 \\
31 & 42 & $\mathrm{i}(3 \mathrm{q})$ & 38 \\
\hline
\end{tabular}

\footnotetext{
* See text.
} 

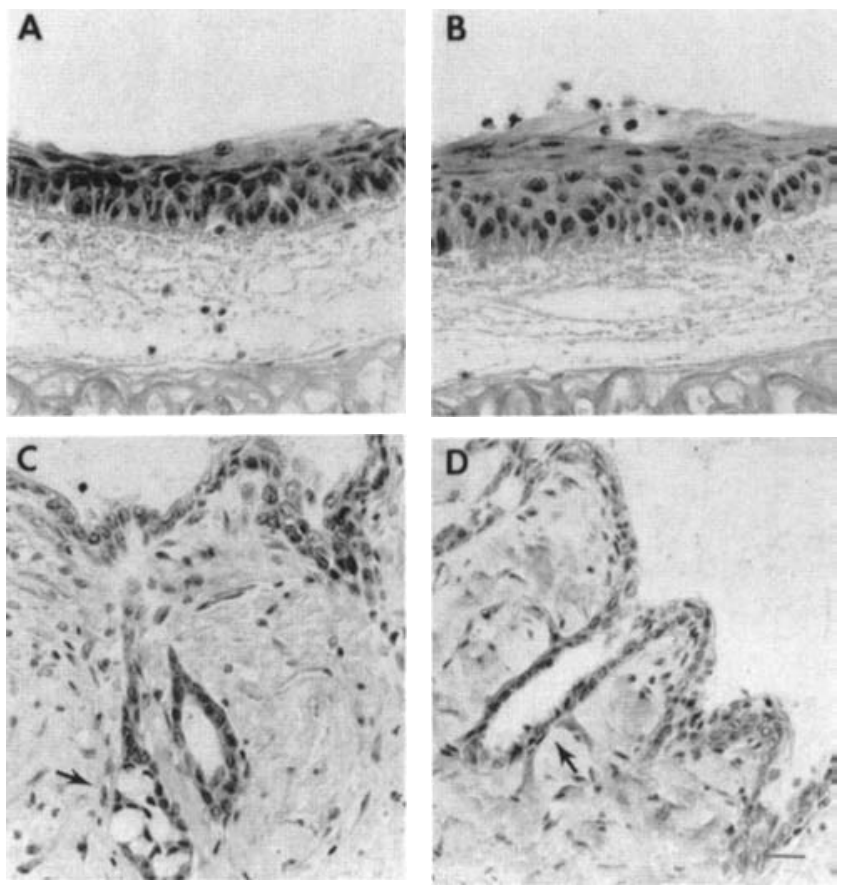

Figure 8. Light microscopy of denuded tracheal grafts repopulated with passage 8 SPOC1 cells. Panels $A$ and $B$ : One week after implantation, cells form a multilayered stratified squamous epithelium, with evidence of keratinization. Panels $C$ and $D$ : Three weeks after implantation, epithelium is less multilayered and more cuboidal and occasionally forms glandular infiltrates into the surrounding tissue (arrows). Tracheal grafts were stained with H\&E. Bar = $20 \mu \mathrm{m}$.

in Figure 9 and summarized in Table 2. Keratin 13, a marker of squamous differentiation (23), was heterogeneously expressed in focal areas by suprabasal cells in both Day 7 and Day 21 grafts. Therefore, SPOCl cells in Day 21 tracheal grafts showed evidence of mixed differentiation potential, with some cells displaying a secretory phenotype and others expressing markers of squamous cells. Day 7 grafts showed diffuse staining of the entire epithelium for keratin 14, which is a basal cell marker in normal trachea. Keratin 14 staining in Day 21 grafts was restricted primarily to the basal cell layer. Keratin 19, which is expressed in most normal rat RTE cells, was expressed primarily in suprabasal cells in both Day 7 and Day 21 graft sections, although staining was more uniform at the later time point. Tracheal grafts did not react with the ciliated cell marker RTE3 or with mAb against keratin 18, which stain columnar cells in the intact trachea and differentiated primary RTE cells (data not shown).

\section{Discussion}

Neoplastic and preneoplastic RTE cell lines derived from carcinogen-exposed primary RTE cells have a number of alterations, compared with primary RTE cells. RTE cell lines express decreased requirements for exogenous growth factors and have numerous chromosomal alterations and various degrees of tumorigenicity. All RTE cell lines examined thus far exhibit a keratinizing, stratified, squamous morphology when inoculated into tracheal grafts. SPOC1 cells also have increased proliferative capacity and decreased requirements for exogenous growth factors. Both SPOCl and the other RTE cell lines have alterations in expression and localization of extracellular matrix proteins (14). However, unlike previously characterized RTE cell lines, SPOC1 cells are unique in having a diploid karyotype and, potentially, the capacity to differentiate into both secretory and squamous cell phenotypes both in culture and in tracheal grafts. Therefore, the SPOCl cell line should prove to be a useful tool for studying both differentiation and neoplastic progression of airway epithelial cells.

Transformed cells in vitro often have altered growth factor requirements compared with their normal counterparts (31). The present data indicate that alterations in growth factor requirements occur early during immortalization of RTE cells. Comparison of early-versus late-passage $\mathrm{SPOCl}$ cell growth factor requirements indicates that there may be selection for growth factor independence with time in culture. Therefore, the SPOC1 cell line will be useful in examining the alterations that give rise to changes in growth factor requirements in airway epithelial cells.

We have previously found that exogenous growth factors alter primary RTE cell morphology and extracellular matrix gene expression $(13,30)$. SPOCl cell morphology is altered by withdrawal of growth factors, although not in the same way that primary RTE cells are. Primary RTE cell morphology changes dramatically and Fn RNA levels decrease with removal of EGF and BPE (13). Changes in SPOCl cell morphology and Fn levels, however, are minimal with removal of these factors. On the other hand, withdrawal of insulin from SPOCl cells significantly alters morphology and correlates with increased Fn RNA levels. Insulin has been found to affect extracellular matrix expression in different ways. In $3 \mathrm{~T} 3$ cells, insulin has been shown to increase secretion of Fn protein (32). Fn secretion in other cell types is inhibited by the addition of insulin (33). It will be of interest to determine the role insulin and related growth factors play in regulation of extracellular matrix in SPOC1 cells.

Although normal diploid karyotypes have been identified in enhanced growth variants of RTE cells exposed to carcinogens (16), RTE cell lines derived from these enhanced variants are aneuploid (reference 15 and unpublished observations). The modal chromosome number of SPOC1 cells is diploid at both early and late passages. However, all SPOC1 cells possess nonrandom chromosome changes involving chromosomes 1,2 , and 6 , and a smaller percentage of cells have alterations in chromosome 3. Since SPOC1 cells are not tumorigenic, these chromosome alterations can be associated with immortalization of RTE cells. Previous studies have found that structural and/or numerical alterations in chromosomes 1 and 3 are frequent occurrences in transformed rat cells $(15,34,35)$. Treatment of SPOC1 cells with carcinogens or transfection with transforming oncogenes may help identify molecular alterations associated with neoplastic progression and tumor formation in tracheal epithelial cells.

A frequent criticism of in vitro cell culture models is that dissociation of normal cells and propagation on plastic often renders cells de-differentiated, with growth characteristics very dissimilar from their in vivo state. Although many cells express an altered phenotype in vitro, several systems have 


\section{Day 7}

AB-PAS

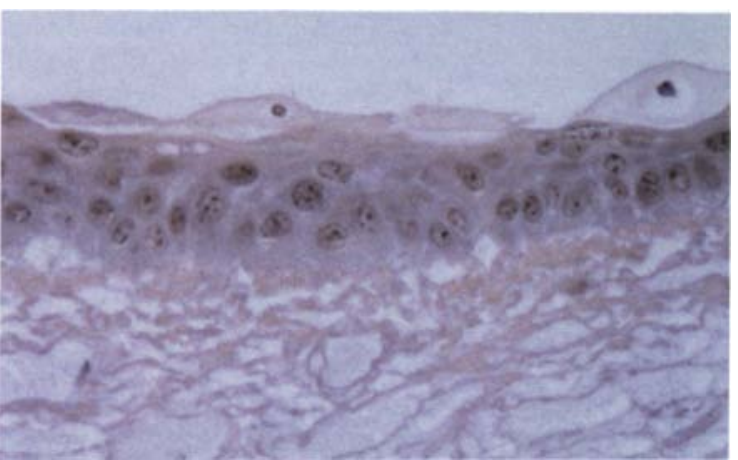

K 13

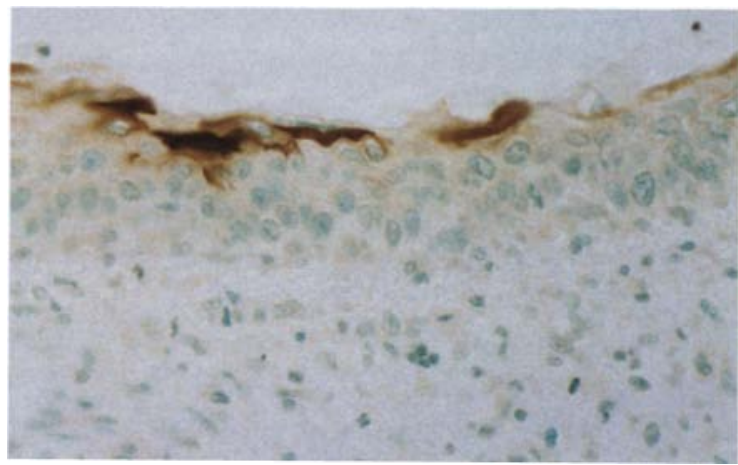

K14

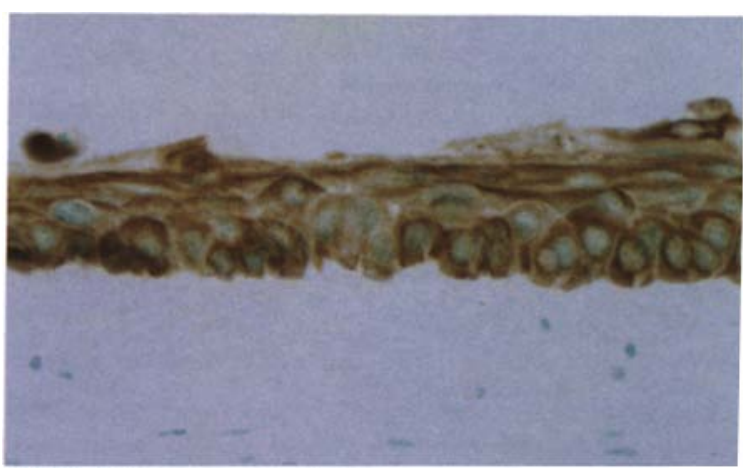

K 19

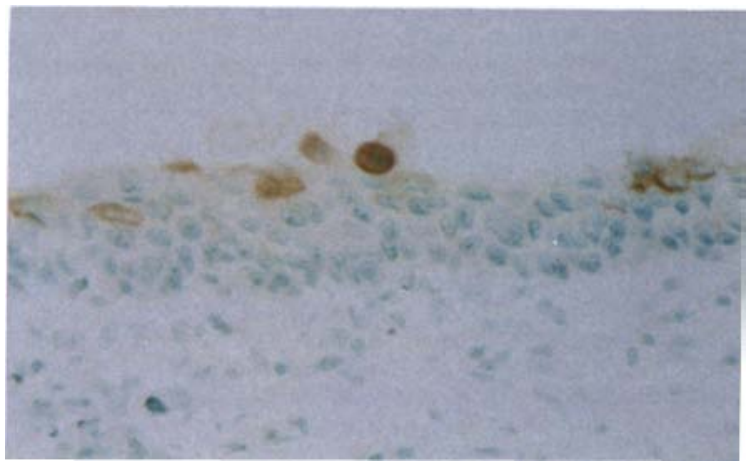

Day 21
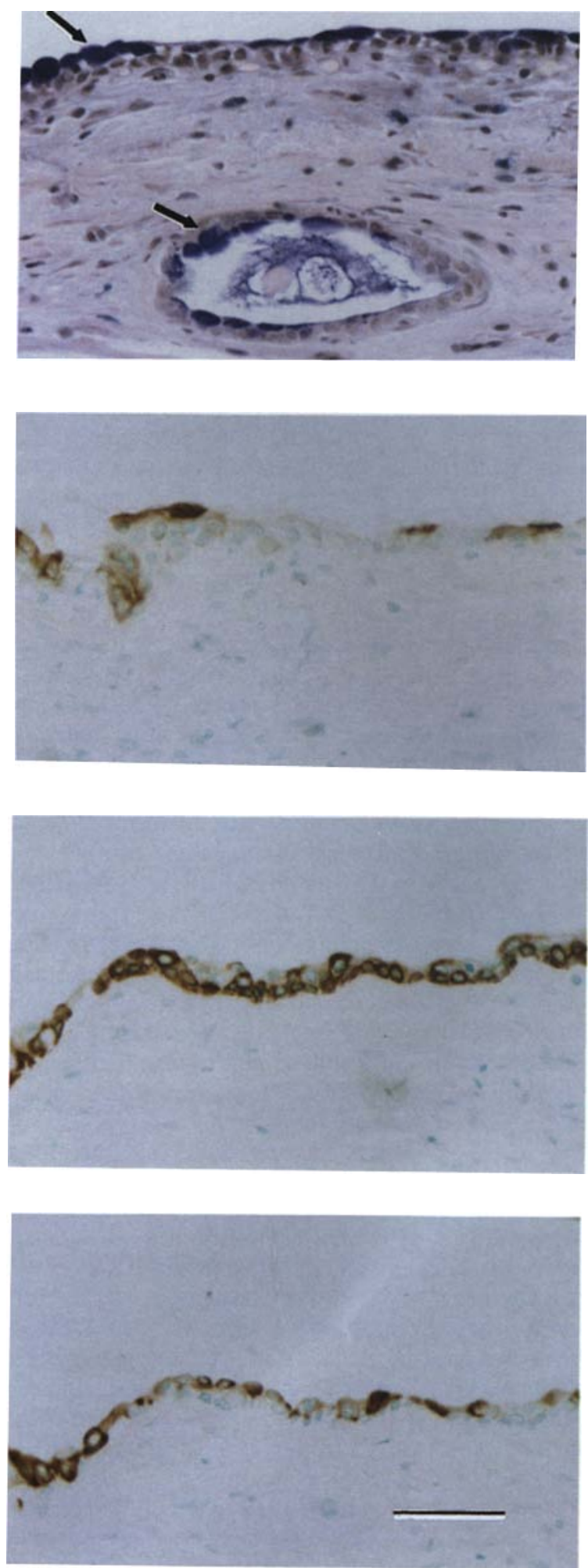

Figure 9. Staining of SPOC1 cells in Day 7 and Day 21 tracheal grafts with AB-PAS and antibodies for keratins 13, 14, and 19. Positive AB-PAS staining is seen only in Day 21 grafts and is localized in cells of the surface epithelium as well as in cells in the glandlike structures (arrow). Keratin 13,14, and 19 staining is observed in both early and late grafts; however, the localization and intensity of staining changes with time (see text). Bar $=50 \mu \mathrm{m}$. These results are summarized in Table 2 . 
TABLE 2

Summary of SPOCI repopulated tracheal graft reactivity with cytochemical markers

\begin{tabular}{|c|c|c|c|c|c|c|}
\hline $\begin{array}{l}\text { Marker } \\
\text { Expression* }\end{array}$ & $\begin{array}{l}\text { AB-PAS: } \\
\text { Secretory } \\
\text { Granules }\end{array}$ & $\begin{array}{c}\text { K13: } \\
\text { Squamous } \\
\text { Differentiation }\end{array}$ & $\begin{array}{l}\text { K14: } \\
\text { Basal } \\
\text { Cells }\end{array}$ & $\begin{array}{l}\text { K18: } \\
\text { Columnar } \\
\text { Cells }\end{array}$ & $\begin{array}{l}\text { K19: } \\
\text { All } \\
\text { Cells }\end{array}$ & $\begin{array}{l}\text { RTE3: } \\
\text { Ciliated } \\
\text { Cells }\end{array}$ \\
\hline Day 7 & - & + & ++ & - & $+1-$ & - \\
\hline Day 21 & + & + & + & - & + & - \\
\hline
\end{tabular}

* In normal rat trachea (22).

++ , strongly expressed in most cells; + , strongly expressed in some cells; $+/-$, staining in few cells; - , no staining.

been developed in which some aspect of cellular differentiation is maintained. Cultures of tracheobronchial epithelial cells from a variety of species, including rat (18), maintain structural and functional features of differentiation under the appropriate culture conditions $(10,36-40)$. However, there are few instances of immortalized airway epithelial cell lines that maintain the ability to differentiate into mucociliary epithelium $(9,10,37)$. RTE cells lose their differentiated phenotype (29) as well as their capacity to regenerate denuded tracheas with a pseudostratified epithelium upon culture on plastic for extended periods. Transformed RTE cells reepithelialize tracheas with a keratinizing squamous epithelium containing abundant cellular atypia, which in some cases form invasive squamous cell tumors (17). Repopulation of tracheas with SPOC1 cells yields a unique pattern of differentiation for RTE cell lines. These cells initially form a squamous epithelium, which subsequently gives rise to a more cuboidal, pseudostratified glandular epithelium that reacts with both $A B-P A S$ and keratin $13 \mathrm{mAb}$. Cells also show positive staining with an antibody that recognizes keratin 19 , which has been shown to be widely expressed in both stratified and simple epithelia (41). SPOCl cells show no evidence of ciliated cell differentiation and have lost K18 antigenicity, a marker of columnar epithelial cells in rat trachea $(20,22)$. These characteristics make SPOC1 cells a unique system with which to study the molecular and cellular events associated with airway epithelial cell differentiation.

In conclusion, the SPOC1 cell line expresses characteristics that are similar to those seen in other RTE cell lines, including decreased growth factor requirements and alterations in extracellular matrix expression. However, these cells also have traits not expressed by other RTE cell lines, including a diploid karyotype and the ability to form both squamous and glandular epithelium. Therefore, $\mathrm{SPOCl}$ cells may provide a window into very early changes occurring during multistep neoplastic progression of airway epithelial cells. Injury (either physical or chemical) of the tracheobronchial epithelium can result in squamous cell metaplasia, and similar changes in differentiation pathways are seen in preneoplastic tracheobronchial lesions (11). Since the molecular alterations responsible for modulation of mucosecretory and squamous differentiation in airway epithelium remain uncertain, the SPOC1 cells should prove to be a valuable model system with which to study the relationship between airway cell differentiation state and neoplastic transformation.

Acknowledgments: The writers thank Dr. R. Hynes for the gift of Fn cDNA, Mr. D. Rusnak and Ms. V. Madden for excellent technical assistance, and Dr. B. Libbus for cytogenetic analysis.

\section{References}

1. Farber, E. 1984. The multistep nature of cancer development. Cancer Res. 4431:4217-4223.

2. Vogelstein, B., E. R. Fearon, S. R. Hamilton, S. E. Kern, A. Presinger, M. Leppert, Y. Nakamura, R. White, A. M. Smits, and J. L. Bos. 1988. Genetic alterations during colorectal-tumor development. N. Engl. J. Med. 319:525-532

3. Mariassy, A. T. 1992. Epithelial cells of trachea and bronchi. In Comparative Biology of the Normal Lung. R. A. Parent, editor. CRC Press, Boca Raton. 63-76.

4. Blenkinsopp, W. K. 1967. Proliferation of respiratory tract epithelium in the rat. Exp. Cell Res. 46:144-154.

5. Gazdar, A. F., D. N. Carney, E. K. Rusell, H. L. Sims, and S. B. Baylin. 1980. Establishment of continuous clonable cultures of small cell carcinoma of the lung which have amine precursor uptake and decarboxylation properties. Cancer Res. 40:3502-3507.

6. Gruenert, D. C., C. B. Basbaum, M. J. Welsh, W. E. Finkbeiner, and J. A. Nadel. 1988. Characterization of human tracheal epithelial cells transformed by an origin-defective simian virus 40. Proc. Natl. Acad. Sci. USA 85:5951-5955.

7. Yoakum, G. H., J. F. Lechner, E. W. Gabrielson, B. E. Korba, L. MalanShibley, B. F. Trump, and C. C. Harris. 1984. Transformation of human bronchial epithelial cells transfected by Harvey ras oncogene. Science 227:1174-1179.

8. Masui, T., J. F. Lechner, G. H. Yoakum, J. Willey, and C. C. Harris. 1986. Growth and differentiation of normal and transformed human bronchial epithelial cells. J. Cell. Physiol. 4:73-81.

9. Cozens, A. L., M. J. Yezzi, K. Kunzelman, T. Ohrui, L. Chin, K. Eng, K. L. Finkbeiner, J. H. Widdicombe, and D. C. Gruenert. 1994. CFTR expression and chloride secretion in polarized immortal human bronchial epithelial cells. Am. J. Respir. Cell Mol. Biol. 10:38-47.

10. de Jong, P. M., M. A. J. A. van Serkenburg, S. C. Hesseling, J. A. Kempenaar, A. A. Mulder, A. M. Mommaas, J. H. Dijkman, and M. Ponec. 1994. Ciliogenesis in human bronchial epithelial cells cultured at the airliquid interface. Am. J. Respir. Cell Mol. Biol. 10:271-277.

11. Nettesheim, P., and J. C. Barrett. 1984. Tracheal epithelial cell transformation: a model system for studies on neoplastic progression. Crit. Rev. Toxicol. 12:215-239.

12. Ferriola, P. C., C. Walker, A. T. Robertson, H. S. Earp, D. W. Rusnak, and P. Nettesheim. 1989. Altered growth factor dependence and transforming growth factor gene expression in transformed rat tracheal epithelial cells. Mol. Carcinog, 2:336-344.

13. Ferriola, P. C., H. S. Earp, R. DiAugustine, and P. Nettesheim. 1991. Role of TGF $\alpha$ and its receptor in proliferation of immortalized rat tracheal epithelial cells: studies with tyrphostin and TGF $\alpha$ antisera. J. Cell. Physiol. 147:166-175.

14. Carter, C. A., M. M. Doherty, D. W. Rusnak, P. Nettesheim, and P. C. Ferriola. 1994. Alterations in the localization of F-actin, fibronectin and thrombospondin occur prior to neoplastic transformation in rat tracheal epithelial cells. Exp. Cell Res. 212:141-150.

15. Endo, S., P. Nettesheim, and C. Walker. 1990. Nonrandom chromosome alterations that correlate with progression to immortality in RTE cells transformed with MNNG. Cancer Res. 50:740-747.

16. Oshimura, M., D. J. Fitzgerald, H. Kitamura, P. Nettesheim, and J. C. Barrett. 1988. Cytogenetic changes in RTE cells during early stages of carcinogen induced neoplastic progression. Cancer Res. 48:702-708.

17. Terzaghi, M. P., P. Nettesheim, and M. Williams. 1978. Repopulation of denuded tracheal grafts with normal, preneoplastic and neoplastic epithelial cell populations. Cancer Res. 38:4546-4553.

18. Kaartinen, L., P. Nettesheim, K. Adler, and S. Randell. 1993. RTE cell differentiation in vitro. In Vitro Cell. Dev. Biol. 29A:481-492.

19. Committee for a Standardized Karyotype of Rattus norvegicus. 1973. Stan dard karyotype of the Norway rat. Cytogenet. Cell Genet. 12:199-205.

20. Shimizu, T., P. Nettesheim, F. C. S. Ramaekers, and S. H. Randell. 1992. Expression of cell-type-specific markers during rat tracheal epithelial regeneration. Am. J. Respir. Cell Mol. Biol. 7:30-41. 
21. Randell, S. H., T. Shimizu, W. Bakewell, F. C. S., Ramaekers, and P. Nettesheim. 1993. Phenotypic marker expression during fetal and neonatal differentiation of rat tracheal epithelial cells. Am. J. Respir. Cell Mol. Biol. 8:546-555.

22. Shimizu, T., P. Nettesheim, E. M. Eddy, and S. H. Randell. 1992. Monoclonal antibody markers for subpopulations of RTE cells. Exp. Lung Res. 18:323-342.

23. Jetten, A., M. D. George, and H. L. Smits. 1989. Keratin 13 is linked to squamous differentiation in rabbit tracheal epithelial cells and downregulated by retinoic acid. Exp. Cell Res. 182:622-634

24. Chirgwin, J., A. Przybyla, R. MacDonald, and W. Rutter. 1979. Isolation of biologically active ribonucleic acid from sources enriched in ribonucleases. Biochemistry 18:5294-5299.

25. Lehrach, H., D. Diamond, J. M. Wozney, and H. Boedtker. 1977. RNA molecular weight determinations by gel electrophoreses under denaturing conditions: a critical reexamination. Biochemistry 18:4743-4751.

26. Ferriola, P. C., A. T. Robertson, D. W. Rusnak, R. DiAugustine, and P. Nettesheim. 1992. EGF dependence and TGFa autocrine growth regulation in primary rat tracheal epithelial cells. J. Cell. Physiol. 152:302-309.

27. Schwarzbauer, J. E., J. W. Tamkun, I. R. Lemischka, and R. O. Hynes. 1983. Three different fibronectin mRNAs arise by alternative splicing within the coding region. Cell 35:421-431.

28. Kitamura, H., D. J. Fitzgerald, L.-A. Li, J. C. Barrett, and P. Nettesheim. 1986. Morphological characterization of transformed colonies in rat tracheal epithelial cell cultures exposed to carcinogen. Cancer Res. 46: 4631-4641.

29. Chang, L.-Y., R. Wu, and P. Nettesheim. 1985. Morphological changes in RTE cells during the adaptive and early growth phase in primary cell culture. J. Cell Sci. 74:283-301.

30. Ferriola, P. C., C. A. Carter, D. W. Rusnak, and P. Nettesheim. 1992. Regulation of cytoskeletal and ECM components by the TGFa/EGF receptor pathway in rat tracheal epithelial cells. Mol. Biol. Cell 3:233a.
31. Holley, R. W. 1975. Control of growth of mammalian cells in cell culture. Nature 258:487-490.

32. Guller, S., D. L. Allen, R. E. Corin, C. J. Lockwood, and M. Sonnenberg. 1992. Growth hormone and fibronectin expression in 3T3 preadipose cells. Endocrinology 130:2609-2616.

33. Dorrington, J. H., J. J Bendell, A. Chuma, and D. K. Lobb. 1987. Actions of growth factors in the follicle. J. Steroid Biochem. Mol. Biol. 27: $405-411$.

34. Ahlstrom, U. 1974. Chromosomes of primary carcinomas induced by 7,12-dimethylbenz(a)anthracene in the rat. Hereditas 78:235-244.

35. Levan, G., and A. Levan. 1975. Specific chromosome alterations in malig nancy: studies in rat sarcomas induced by two polycyclic hydrocarbons. Hereditas 79:161-198

36. Fiedler, M. A., C. S. Kaetzel, and P. B. Davis. 1991. Sustained production of secretory component by human tracheal epithelial cells in primary culture. Am. J. Physiol. (Lung Cell. Mol. Physiol.) 5:L255-L261.

37. Chopra, D., J. Sullivan, J. Wile, and K. Siddiqui. 1987. Propagation of differentiating normal human tracheobronchial epithelial cells in serumfree medium. J. Cell. Physiol. 130:173-181.

38. Whitcutt, M. J., K. B. Adler, and R. Wu. 1988. A biphasic chamber system for maintaining polarity of differentiation of cultured respiratory tract epithelial cells. In Vitro Cell. Dev. Biol. 24:420-428.

39. Wu, R. W. R, Martin, and C. B. Robinson, 1990. Expression of mucin synthesis and secretion in human TBE cells grown in culture. Am. J Respir. Cell Mol. Biol. 3:467-478.

40. Niles, R., K. C. Kim, T. Hyman, T. Christensen, K. Wasano, and J. Brody. 1988. Characterization of extended primary and secondary cultures of hamster tracheal epithelial cells. In Vitro Cell. Dev. Biol. 24:457-463.

41. Stasiak, P. C., P. E. Purkis, I. M. Leigh, and E. B. Lane. 1989. Keratin 19: predicted amino acid sequence and broad tissue distribution suggest it evolved from keratinocyte keratins. $J$. Invest. Dermatol. 92:707-716. 